\title{
CRIPTOMELANA CUPRÍFERA FORMADA DURANTE O INTEMPERISMO DAS ROCHAS DA JAZIDA DE COBRE DO SALOBO $3 \alpha$, SERRA DOS CARAJÁS
}

\section{RESUMO}

Estudos geoquímicos e mineralógicos do manto de alteração intempérica sobre rochas mineralizadas em cobre do Salobo $3 \alpha$, Serra dos Carajás, mostraram que o cobre liberado dos sulfetos por dissolução é, em grande parte, fixado no perfil de intemperismo e localizado em três principais fases mineralógicas: fase silicatada, fase ferruginosa e fase manganesífera. Apenas a fase manganesífera é objeto deste estudo. Trata-se de uma fase monominerálica, identificada como criptomelana, do grupo da hollandita, com teores variáveis de potássio. Diferentes técnicas analíticas (difração de raios-X, espectrometria infravermelho e microssonda eletrônica) foram utilizadas para caracterizar esta criptomelana e mostrar que ela pode conter até mais de $20 \%$ de $\mathrm{Cu} 0$.

\section{ABSTRACT}

Geochemical and mineralogical studies of the weathering mantle over the copper mineralized rocks of Salobo $3 \alpha$, Serra dos Carajás, Brazil, show that copper, released from sulfides by dissolution, accumulates in situ, and is mainly located in three mineralogical phases: silicatic, ferruginous and manganesiferous. Only the manganesiferous phase is treated here. It is a cryptomelane phase (hollandite group) with variable potassium content. Diverse methods (X-ray diffraction, infra-red spectrometry, chemical microprobe) show clearly that cryptomelane contains up to $20 \% \mathrm{Cu0}$.

\section{INTRODUÇÃO}

O depósito cuprífero do Salobo $3 \alpha$ (Serra dos Carajás) (Fig. 1) é constituído por uma seqüência de rochas metassedimentares (xistos com granada, anfibólio e biotita e formação ferrífera da Seqüência Salobo-Pojuca), mineralizadas por sulfetos de cobre que ocorrem disseminados ou em níveis milimétricos a centimétricos, concordantes com as estruturas das rochas.

Este depósito é recoberto por um manto de alteração espesso, da ordem de algumas dezenas de metros, produto do intemperismo daquelas rochas sob condições climáticas agressivas. O perfil de alteração (Fig. 2) conserva aproximadamente os teores médios do minério primário $(1,05 \%$ $\mathrm{Cu} 0$ para o minério sulfetado e $0,96 \% \mathrm{Cu} 0$ para o minério alterado, segundo dados da DOCEGEO - FARIAS \& SAUERESSIG, 1982).

Os principais minerais encontrados são interestratificados, vermiculita, caulinita, esmectita, goethita, malaquita e criptomelana, além dos minerais residuais quartzo e magnetita. Em grande parte, o perfil é uma isalterita.

O cobre contido no material intemperizado não é devido a minerais de cobre originados no decorrer do intemperismo, como sulfatos, silicatos e óxidos, que são inexistentes no Salobo, mas que são freqüentes em outros perfis de alteração sobre jazidas sulfetadas de cobre (KOUD, 1985). Por outro lado, ocorre carbonato de cobre (malaquita), mas apenas localmente e em quantidades reduzidas, principalmente na base do perfil, na zona de contato entre rocha sã e rocha alterada. Sua ocorrência não justifica os teores de cobre encontrados no material alterado.

Trabalhos anteriores (TOLEDO-GROKE, 1986; PARISOT, 1989) concluíram que o cobre, a partir da sua liberação quando da dissolução dos sulfetos primários, é fixado em diversas fases secundárias, geradas por neoformação ou transformação, fenômenos estes ligados à evolução supérgena dos minerais primários de maneira direta (formação de pseudomorfoses) ou indireta (remobilização dos produtos de alteração e fixação posterior). Assim, o cobre é fixado, além da malaquita, em:

a) fases silicáticas: produtos de transformação das biotitas, sobretudo minerais tipo vermiculita e interestratificados $B-V$ (pseudomorfo- 


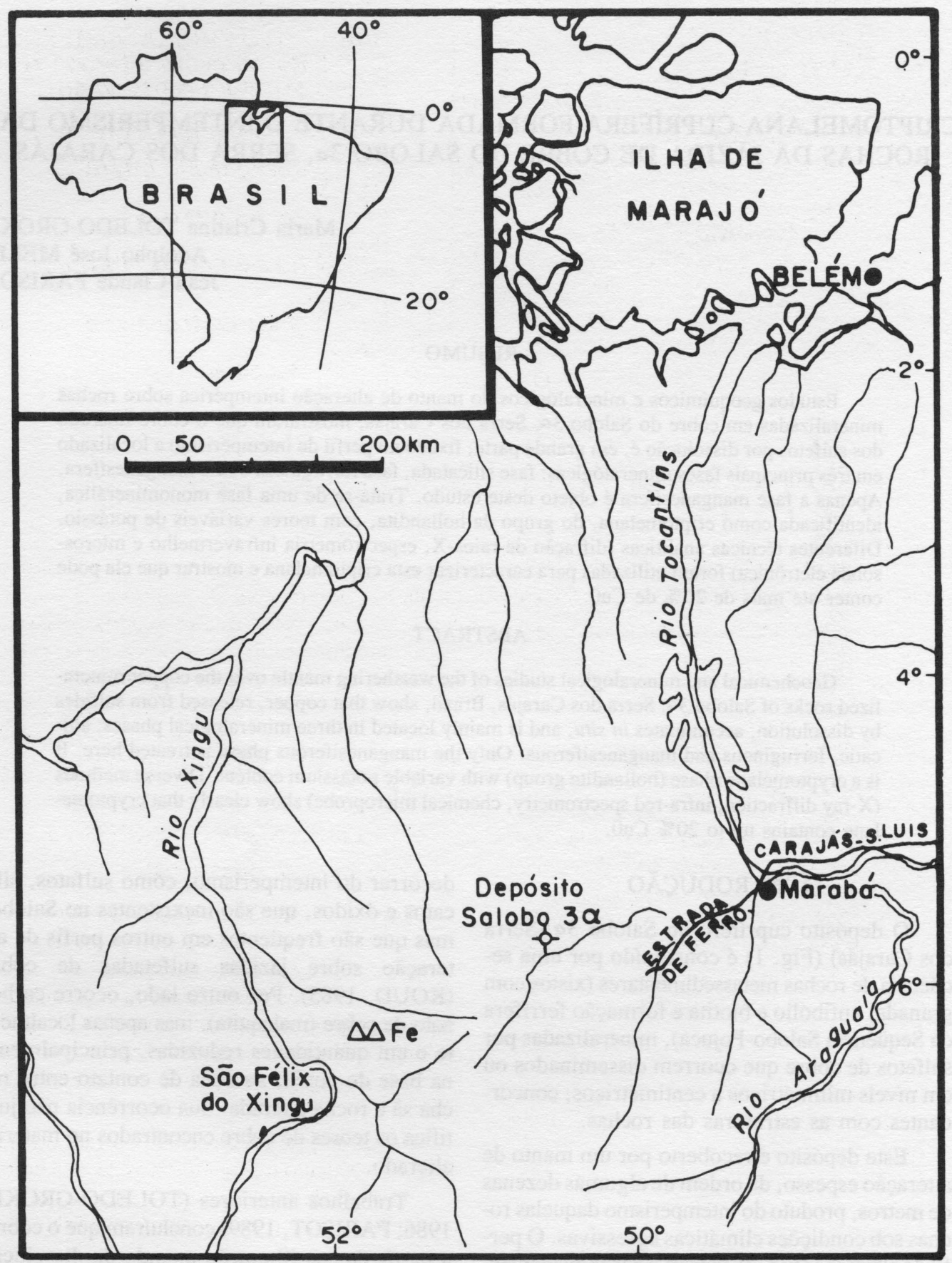

FIGURA 1 - Mapa de localização do depósito Salobo 3 $\alpha$, Serra dos Carajás. (Fonte: DOCEGEO.) 


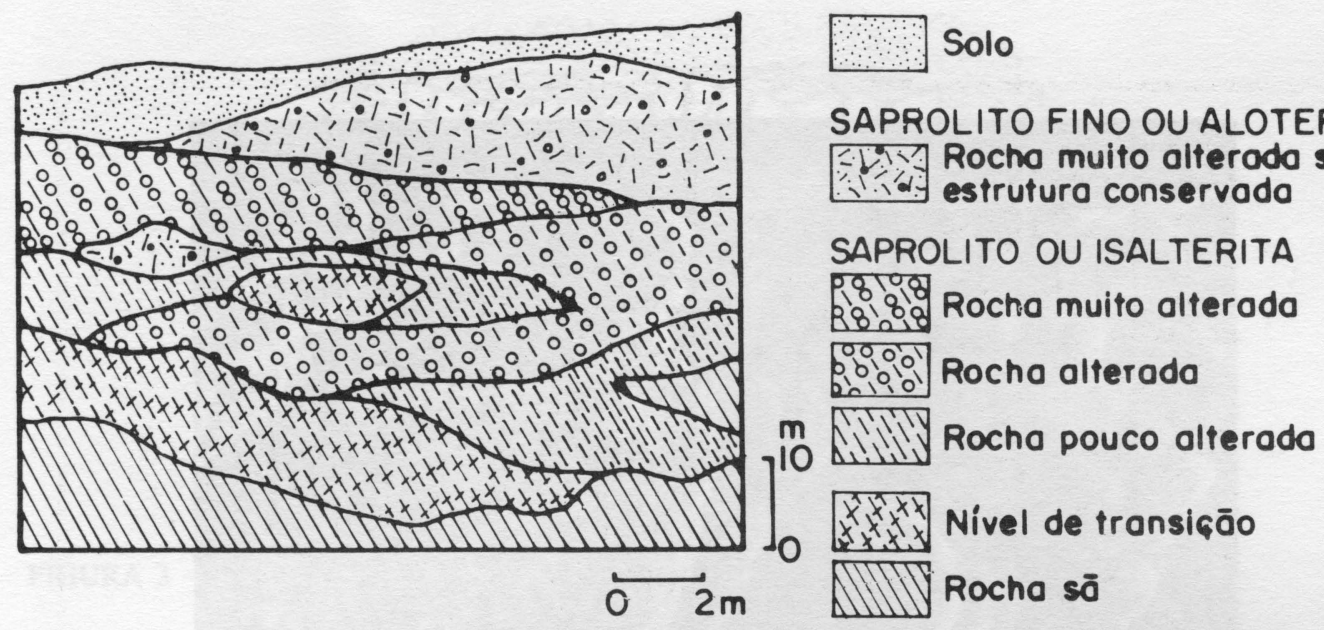

FIGURA 2 - Perfil típico idealizado de alteração sobre as rochas mineralizadas em cobre do Salobo $3 \alpha$, Serra dos Carajás.

ses), com até $18 \% \mathrm{Cu} 0$, e esmectitas verdes do tipo nontronita (sistema fissural), com até $5 \% \mathrm{Cu} 0$;

b) fases ferruginosas: oxi-hidróxidos de ferro (pseudomorfoses de granada e anfibólio, sistema fissural e plasma secundário argiloferruginoso), com até $6 \% \mathrm{Cu} 0$;

c) fase manganesífera: mineral tipo criptomelana (grupo da hollandita), do sistema fissural, com até $25 \% \mathrm{Cu} 0$.

Segundo VEIGA (1983), os oxi-hidroxidos de ferro são responsáveis por $80 \%$ do cobre fixado no perfil de alteração como um todo. Por outro lado, PARISOT (1989) afirma que, nos horizontes com estrutura conservada, que representam o essencial do manto de alteração, a maior parte do cobre está ligada à fase tipo vermiculita.

Paralelamente a esta discussão quantitativa, coloca-se o problema da associação do cobre aos produtos neoformados manganesíferos, problema ainda pouco explorado na literatura especializada.

Este trabalho trata exclusivamente da caracterização desta fase manganesífera e da discussão de sua associação com o cobre.

\section{MATERIAIS E MÉTODOS}

O produto manganesífero supérgeno apresenta um caráter textural típico de iluviação. Ocorre como preenchimento cutânico de fissuras (Foto 1), cavidades e descontinuidades inter, intra e transminerais, sobretudo associado às biotitas em vias de alteração (Foto 2). Pode constituir películas delgadas bem distintas e individualizadas, ou impregnar o material encaixante, a ele se associando de tal forma que se torna muito difícil ou mesmo impossível separálo em certas amostras.
Sobre este material, identificado primeiramente nas observações de campo e ao microscópio óptico, foram executados diversos procedimentos analíticos, visando à sua caracterização: difratometria de raios-X, cálculo de parâmetros de cela unitária, microscopia óptica e eletrônica de varredura, microssonda eletrônica e espectroscopia de absorção no infravermelho.

\section{RESULTADOS E DISCUSSÃO}

\subsection{Caracterização do material}

Conforme indicam os dados de difratometria de Raios-X e espectroscopia de absorção no infravermelho, o produto manganesífero constitui uma fase monominerálica, identificada como criptomelana, sendo um mineral do grupo da hollandita, de estrutura de inomanganato de quatro cadeias duplas (POTTER \& ROSSMAN, 1979) (Fig. 3).

Os difratogramas de raios-X foram utilizados para o cálculo dos parâmetros de cela unitária, que podem ser comparados com os resultados obtidos por outros autores (Tabela 1).

$\mathrm{O}$ espectro de absorção no infravermelho (Fig. 4) é similar àqueles obtidos para minerais do grupo da hollandita, particularmente a criptomelana.

Análises químicas qualitativas (Foto 2 e Fig. 5) e quantitativas (Tabela 2) mostram a associação entre o cobre e o mineral em questão. A presença eventual de $\mathrm{Fe}_{2} \mathrm{O}_{3}, \mathrm{SiO}_{2}$ e $\mathrm{Al}_{2} \mathrm{O}_{3}$ foi interpretada como influência dos minerais sobre os quais se instalou a criptomelanna, devido à sua fraca individualização, ou ainda como possíveis impurezas durante a cristalização, já que aque- 


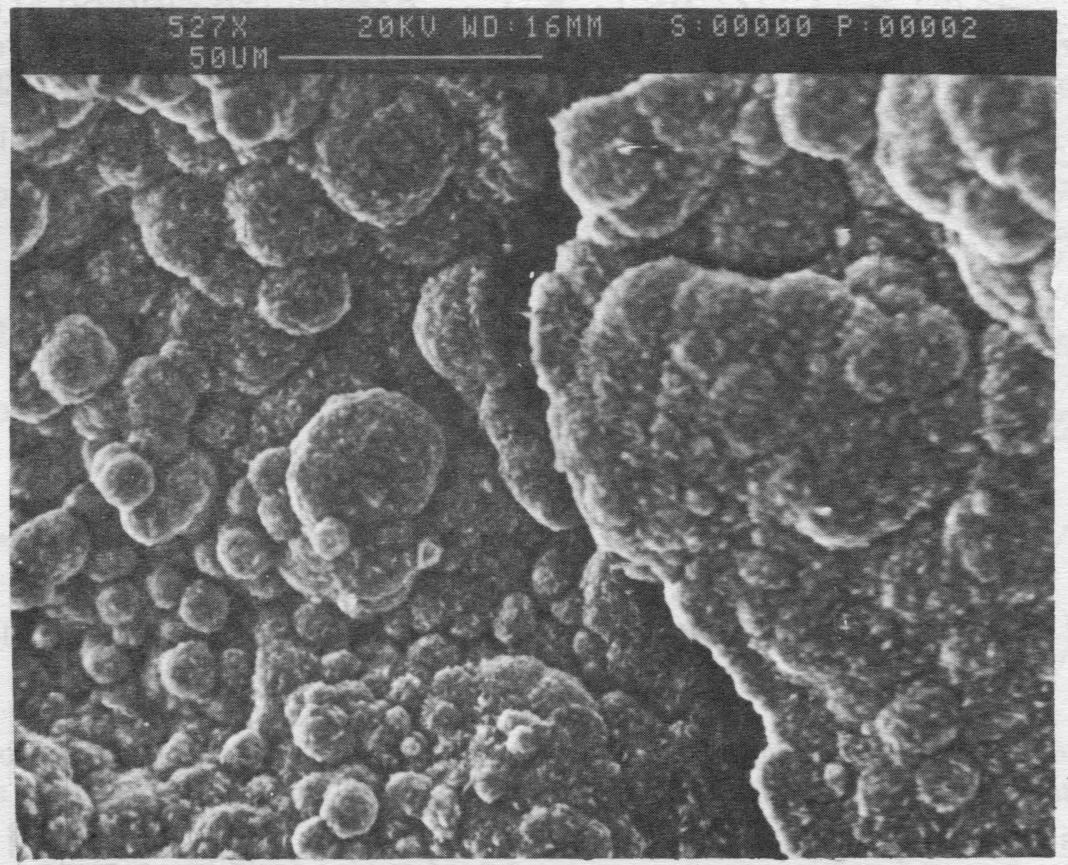

FOTO 1 - Criptomelana do sistema fissural, apresentando hábito botrioidal (Microscópio Eletrônico de Varredura).

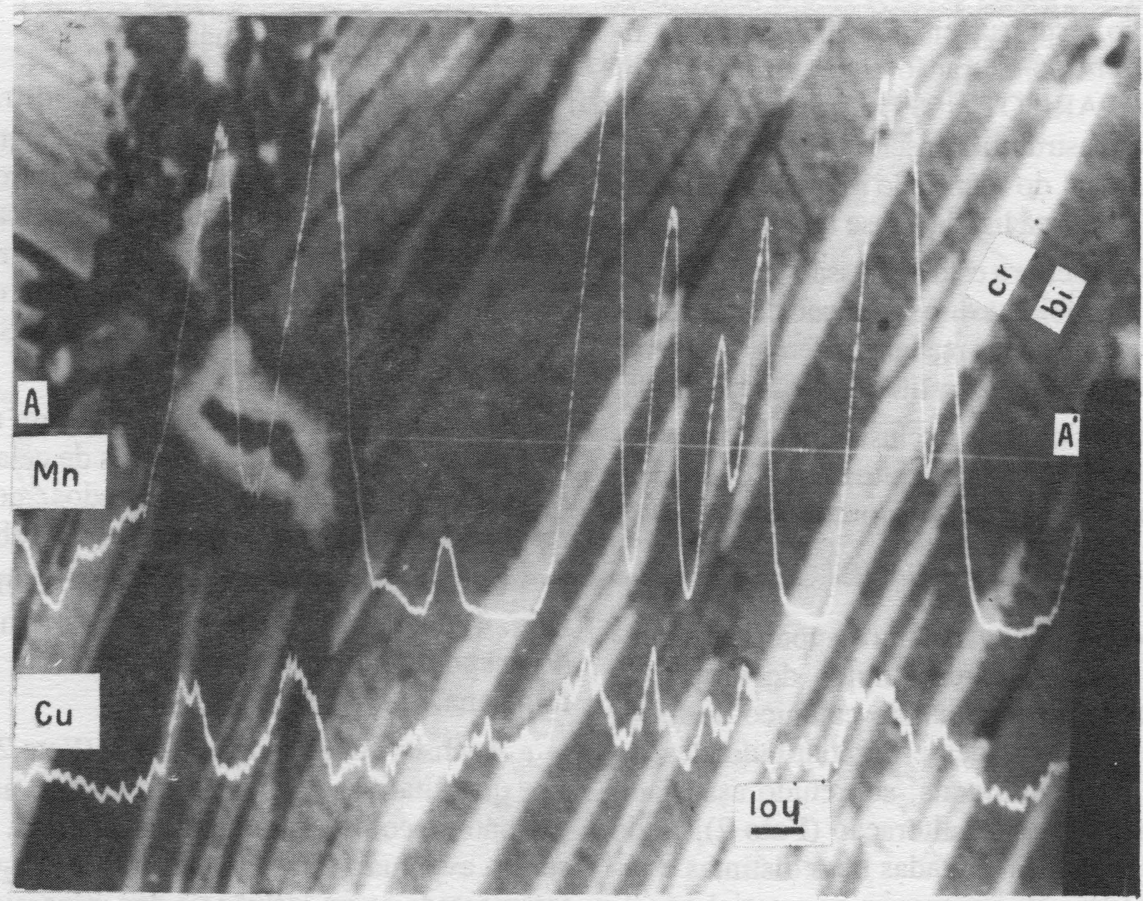

FOTO 2 - Criptomelana (cr) nos espaços interlamelares de biotita (bi), com análise química qualitativa para $\mathrm{Mn}$ e $\mathrm{Cu}$, ao longo do perfil AA' (Microssonda Eletrônica). 


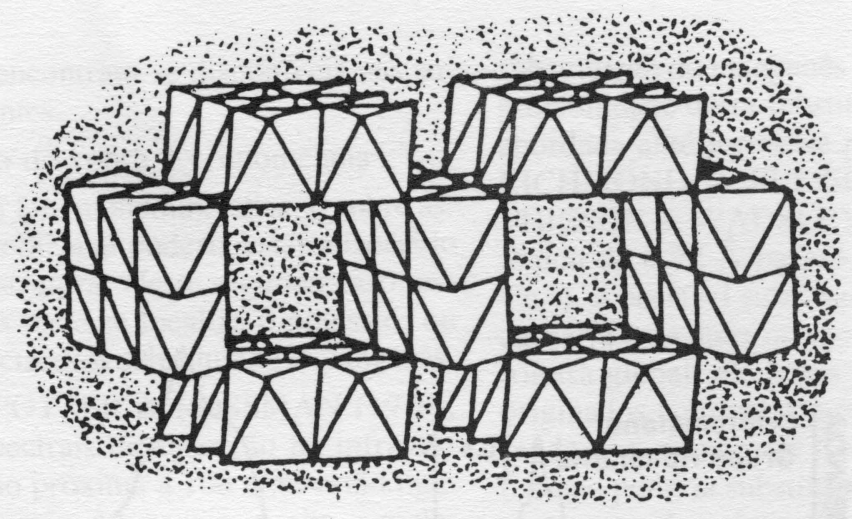

FIGURA 3 - Estrutura da criptomelana, segundo POTTER \& ROSSMAN (1979).

TABELA 1 - Parâmetros de cela unitária, calculados para a criptomelana do Salobo [(9) e (10)], a partir de dados de DRX, comparados com resultados obtidos por outros autores.

\begin{tabular}{lcccccccccc}
\hline & $(1)$ & $(2)$ & $(3)$ & $(4)$ & $(5)$ & $(6)$ & $(7)$ & $(8)$ & $(9)$ & $(10)$ \\
\hline $\mathrm{a}_{\mathrm{o}}=\mathrm{b}_{\mathrm{o}}$ & 9,82 & 9,82 & 9,84 & 9,83 & 9,86 & 9,83 & 9,84 & 9,853 & 9,878 & 9,881 \\
$\mathrm{c}_{\mathrm{O}}$ & 2,86 & 2,83 & 2,85 & 2,862 & 2,86 & 2,84 & 2,85 & 2,840 & 2,841 & 2,836 \\
\hline
\end{tabular}

Fontes: (1) Ramsdell (1942) e Buser \& Graf (1955, in Hypolito, 1980)

(2) Richmond \& Fleischer (1942)

(3) Byström \& Byström (1950)

(4) Butler \& Thirsk (1952)

(5) Valarelli (1967)

(6) Hypolito (1980)

(7) ASTM

(8) Beauvais (1984)

(9) e (10) parâmetros calculados para amostras do Salobo $3 \alpha$

TABELA 2 - (a) Microanálises químicas do produto manganesífero portador de cobre (criptomelana), em porcentagem-peso dos óxidos (Microssonda Eletrônica). O fechamento das análises, distante de $100 \%$, é devido à própria natureza do material intemperizado, hidratado e com alta porosidade, ocupada por resina. (b) Os mesmos dados, com teores corrigidos a $100 \%$.

\begin{tabular}{lrrrrrrrrrrrrrr}
\hline & 1 & 2 & 4 & 44 & 45 & 46 & 48 & 49 & 43 & $123 \mathrm{D}$ & $124 \mathrm{D}$ & $125 \mathrm{D}$ & 176 & 186 \\
\hline $\mathrm{SiO}_{2}$ & 0,09 & 0,41 & 0,09 & 0,75 & 13,25 & 7,62 & 0,03 & 0,13 & 1,13 & 0,18 & 2,72 & 0,10 & 0,68 & 0,52 \\
$\mathrm{Fe}_{2} \mathrm{O}_{3}$ & 5,41 & 3,93 & 2,05 & 1,70 & 12,32 & 6,83 & 2,73 & 2,31 & 4,87 & 1,82 & 5,31 & 1,87 & 4,02 & 5,12 \\
$\mathrm{~K}_{2} \mathrm{O}$ & 0,12 & 0,09 & 0,27 & 0,48 & 1,43 & 1,31 & 0,28 & 9,40 & 0,51 & 0,21 & 0,46 & 0,33 & 2,12 & 1,31 \\
$\mathrm{Al}_{2} \mathrm{O}_{3}$ & 0,76 & 0,88 & 0,40 & 1,28 & 5,58 & 4,41 & 0,45 & 0,34 & 1,96 & 0,90 & 2,13 & 0,80 & 3,88 & 1,92 \\
$\mathrm{MnO}$ & 28,60 & 13,25 & 48,61 & 43,55 & 30,29 & 38,58 & 45,16 & 48,43 & 20,70 & 53,66 & 48,05 & 50,50 & 57,87 & 53,50 \\
$\mathrm{CuO}$ & 8,89 & 3,68 & 18,38 & 15,67 & 14,33 & 15,75 & 17,63 & 17,86 & 8,74 & 22,18 & 17,31 & 18,96 & 6,44 & 9,63 \\
$\mathrm{BaO}$ & $\mathrm{ND}$ & ND & ND & 1,56 & 0 & 0,78 & 1,32 & 0,64 & 0,39 & ND & ND & ND & ND & ND \\
& 43,87 & 22,24 & 69,80 & 64,99 & 77,20 & 75,28 & 67,60 & 70,11 & 38,30 & 78,95 & 75,98 & 72,11 & 75,01 & 72,00 \\
\hline
\end{tabular}

\begin{tabular}{|c|c|c|c|c|c|c|c|c|c|c|c|c|c|c|}
\hline & 1 & 2 & 4 & 44 & 45 & 46 & 48 & 49 & 43 & 123D & $124 \mathrm{D}$ & $125 \mathrm{D}$ & 176 & 186 \\
\hline $\mathrm{SiO}_{2}$ & 0,21 & 1,84 & 0,13 & 1,15 & 17,16 & 10,12 & 0,04 & 0,19 & 2,95 & 0,23 & 3,58 & 0,14 & 0,91 & 0,72 \\
\hline $\mathrm{Fe}_{2} \mathrm{O}_{3}$ & 12,33 & 17,67 & 2,94 & 2,62 & 15,96 & 9,07 & 4,04 & 3,29 & 12,72 & 2,31 & 6,99 & 2,59 & 5,36 & 7,11 \\
\hline $\mathrm{K}_{2} \mathrm{O}$ & 0,27 & 0,40 & 0,39 & 0,74 & 1,85 & 1,74 & 0,41 & 0,57 & 1,33 & 0,27 & 0,61 & 0,46 & 2,83 & 1,82 \\
\hline $\mathrm{Al}_{2} \mathrm{O}_{3}$ & 1,73 & 3,96 & 0,57 & 1,97 & 7,23 & 5,86 & 0,67 & 0,48 & 5,12 & 1,14 & 2,80 & 1,11 & 5,17 & 2,67 \\
\hline $\mathrm{MnO}$ & 65,19 & 59,58 & 69,64 & 67,01 & 39,24 & 51,25 & 66,80 & 69,08 & 54,05 & 67,97 & 63,24 & 69,41 & 77,15 & 74,31 \\
\hline $\mathrm{CuO}$ & 20,26 & 16,55 & 26,33 & 24,11 & 18,56 & 20,92 & 26,08 & 25,47 & 22,82 & 28,09 & 22,78 & 26,29 & 8,59 & 13,38 \\
\hline \multirow[t]{2}{*}{$\mathrm{BaO}$} & ND & ND & ND & 2,40 & 0 & 1,04 & 1,95 & 0,91 & 1,02 & ND & ND & ND & ND & ND \\
\hline & 100,00 & 100,00 & 100,00 & 100,00 & 100,00 & 100,00 & 99,99 & 99,99 & 100,01 & 100,01 & 100,00 & 100,00 & 100,00 & 100,00 \\
\hline
\end{tabular}




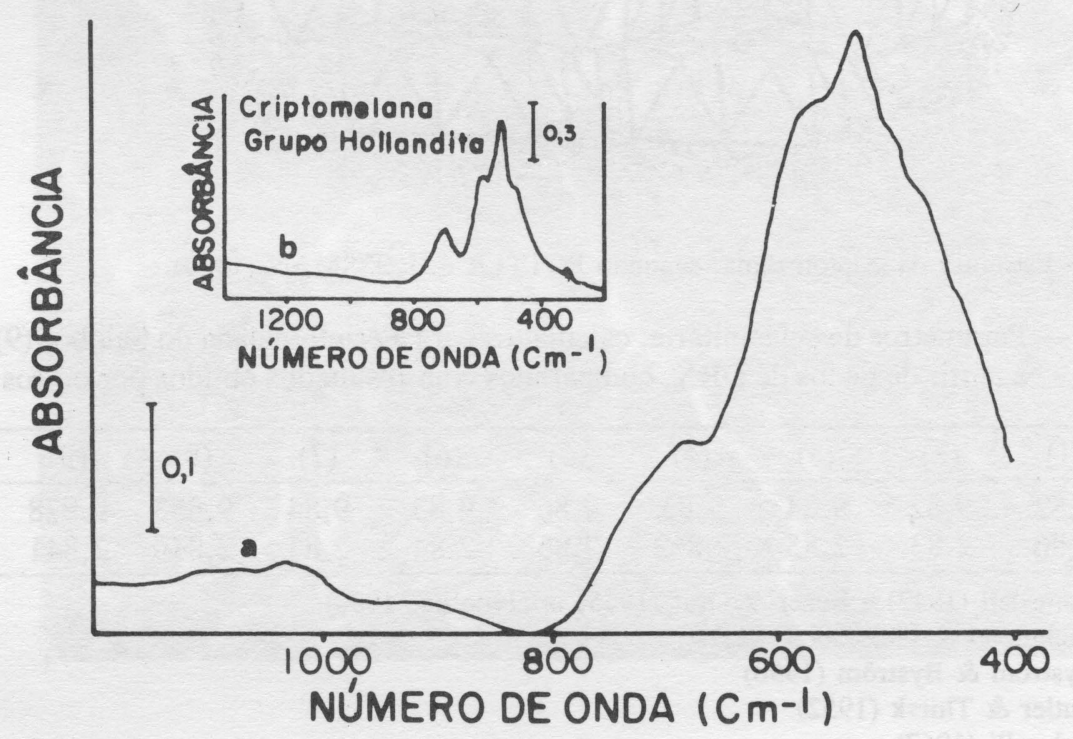

FIGURA 4 - Espectro de absorção no infravermelho para a criptomelana do Salobo: a) criptomelana do Salobo $3 \alpha$; b) criptomelana (POTTER \& ROSSMAN, 1979).

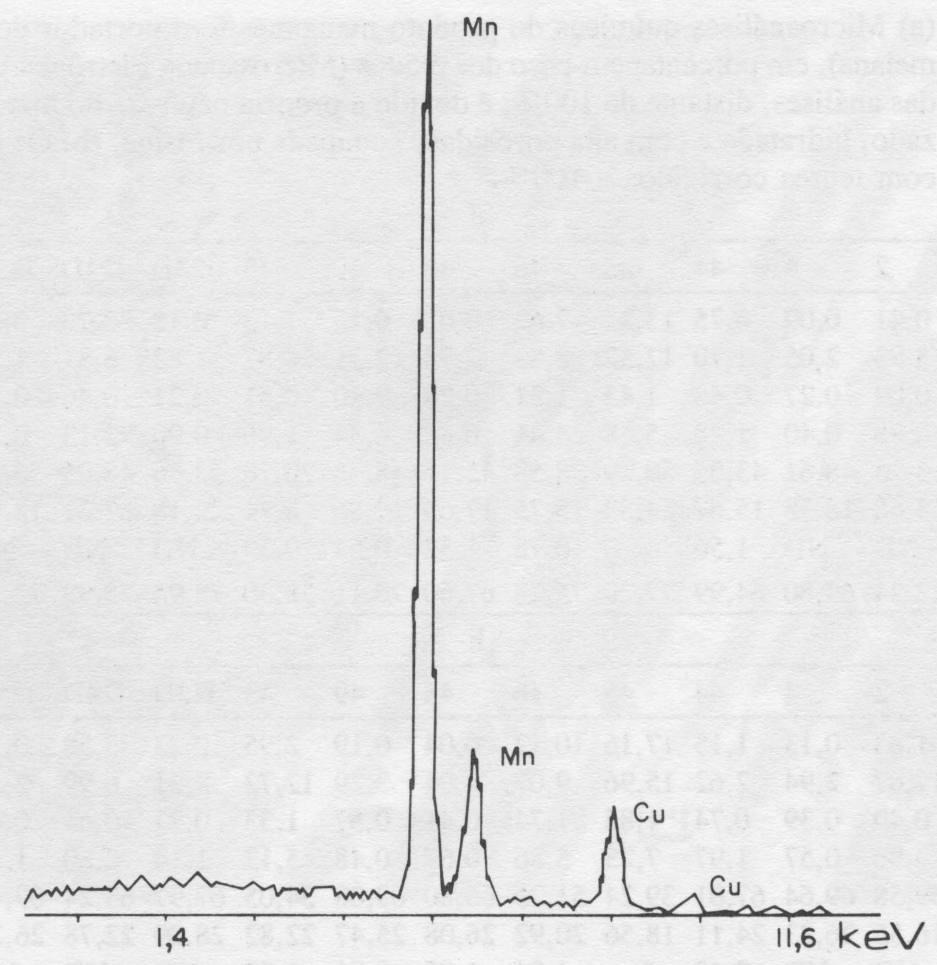

FIGURA 5 - Análise química qualitativa (EDS) da criptomelana do Salobo. 
les elementos encontram-se disponíveis nas soluções percolantes.

\subsection{Associação do cobre à criptomelana}

Sendo uma fase monominerálica, o cobre associado à criptomelana poderia estar adsorvido ou dentro da estrutura. Neste segundo caso, estaria nos túneis onde se localiza o potássio, ou no centro dos octaedros substituindo o manganês.

Segundo POTTER \& ROSSMAN (1979), os padrões espectrais de absorção no infravermelho na região próxima a $100 \mathrm{~cm}^{-1}$ estão ligados aos constituintes dos canais. Assim, aqueles autores encontraram uma absorção a $97 \mathrm{~cm}^{-1}$ para a hollandita com bário como cátion ocupante dos canais e a $136 \mathrm{~cm}^{-1}$ para a criptomelana com potássio ocupando esta posição. Entretanto, não foi possível obter-se um espectro que abrangesse a região além de $400 \mathrm{~cm}^{-1}$ durante a realização desta pesquisa e assim caracterizar as absorções nesta região que dariam informações sobre os cátions dos canais na criptomelana do Salobo.

Os cálculos dos parâmetros de cela unitária (Tabela 1) indicam valores que podem sugerir uma deformação da estrutura do mineral. Esta deformação seria compreensível no caso de uma substituição do manganês por outro elemento. A possibilidade desta substituição pelo cobre já foi abordada anteriormente por GRUNER (1943), RICHMOND \& FLEISCHER (1942) e MATHIESON \& WADSLEY (1950); com um raio iônico de $0,72 \AA$ para o $\mathrm{Cu}^{2+}(0,96 \AA$ para o $\left.\mathrm{Cu}^{+}\right)$, a possível substituição do $\mathrm{Mn}^{4+}(0,60 \AA \bar{\AA})$ causaria uma deformação nos octaedros e na estrutura global, além dos problemas que seriam originados ao nível das cargas. Por outro lado, sendo bem menor que o potássio $(1,33 \AA$ ) , o cobre não poderia substituir este último nos túneis em seu papel estabilizador da estrutura. Não obstante, existem espaços vazios nestas posições, onde o cobre poderia se alojar, coordenando-se com os oxigênios ou hidroxilas dos octaedros. Segundo MACKENZIE (1971), o conteúdo em potássio nas criptomelanas nunca excede $50 \%$ do total de sua capacidade em ocupar os vazios dos túneis da rede cristalina. A relação entre os teores em $\mathrm{Cu} 0$ e em $\mathrm{K}_{2} \mathrm{O}$ (Fig. 6), obtidos em análises pontuais à Microssonda Eletrônica, mostra uma tendência inversamente proporcional, o que poderia sugerir que o cobre estaria ocupando posições do potássio. Já a relação entre os teores em $\mathrm{CuO}$ e em $\mathrm{BaO}$, com os poucos dados disponíveis, não chega a mostrar nenhuma tendência.

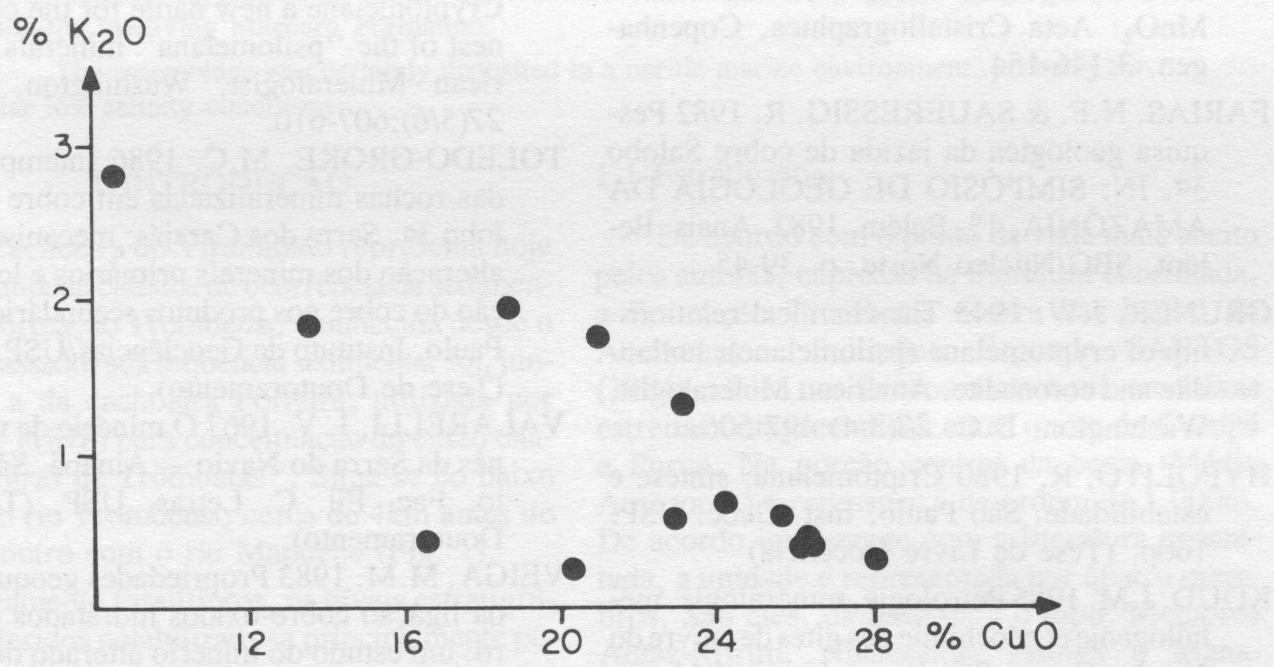

FIGURA 6 - Diagrama $\% \mathrm{~K}_{2} \mathrm{O} \times \% \mathrm{CuO}$ para várias análises pontuais à Microssonda Eletrônica, sobre a criptomelana do Salobo.

Têm-se, portanto, indícios de que o cobre estaria ocupando tanto posições nos túneis da estrutura (posições do $\mathrm{K}$ e Ba) como no centro dos octaedros (posição do $\mathrm{Mn}$ ).

\section{CONCLUSÕES}

Conforme trabalhos anteriores (TOLEDOGROKE, 1986; PARISOT, 1989), todas as fa- ses secundárias formadas neste perfil, em meio rico em cobre proveniente da desestabilização dos sulfetos, servem de suporte para a fixação parcial deste elemento, impedindo sua dispersão no meio superficial. A única exceção é a caulinita, que se forma nos níveis mais evoluídos.

$\mathrm{O}$ produto manganesífero, estudado neste trabalho e identificado como criptomelana, apre- 
senta uma composição química particular: até $28 \%$ em $\mathrm{CuO}$, teores variáveis em $\mathrm{K}_{2} \mathrm{O}$ e $\mathrm{BaO}$, e presença eventual de traços de $\mathrm{Fe}_{2} \mathrm{O}_{3}, \mathrm{Al}_{2} \mathrm{O}_{3}$ e $\mathrm{SiO}_{2}$. Todos estes óxidos estão disponíveis no perfil, a partir da desestabilização dos minerais primários.

A natureza cristaloquímica da associação do cobre com a criptomelana não pode ainda ser precisamente indicada. Estudos cristaloquímicos mais sofisticados poderão indicar a precisa po- sição do cobre na estrutura da criptomelana do Salobo.

\section{AGRADECIMENTOS}

Os autores agradecem à $\mathrm{FAPESP}$ e ao $\mathrm{CNPq}$ pelo suporte financeiro, à DOCEGEO pela assistência aos trabalhos de campo e ao IPT, BRGM (França) e ORSTOM (França) pelas facilidades laboratoriais.

\section{REFERÊNCIAS BIBLIOGRÁFICAS}

BEAUVAIS, A. 1984 Concentrations manganesifères latéritiques. Etude pétrologique de deux gîtes sur roches sédimentaires précambriennes. Gisements de Moanda (Gabon) et d'Azul (Brésil). Thèse $3^{\text {ème }}$ cycle. Un. Poitiers (França).

BUTLER, G. \& THIRSK, H. R. 1952 Electron diffraction evidence for the existence and fine structure of a cryptomelane modification of manganese dioxide prepared in the absence of potassium. Acta Cristallographica, Copenhagen, 5:288-291.

BYSTRÖM, A. \& BYSTRÖM, A. M. 1950 Thel crystal structure of hollandite, the related manganese oxide minerals and $\alpha$ $\mathrm{MnO}_{2}$. Acta Cristallographica, Copenhagen, 3:146-154.

FARIAS, N.F. \& SAUERESSIG, R. 1982 Pesquisa geológica da jazida de cobre Salobo $3^{\alpha}$. IN: SIMPÓSIO DE GEOLOGIA DA AMAZÔNIA, 1․, Belém, 1982. Anais. Belém, SBG/Núcleo Norte. p. 39-45.

GRUNER, J.W. 1943 The chemical relationship of cryptomelane (psilomelane), hollandite and coronadite. American Mineralogist, Washington, D.C. 28(3/4):497-506.

HYPOLITO, R. 1980 Criptomelana: síntese e estabilidade. São Paulo, Inst. Geoc. USP. 160p. (Tese de Livre Docência)

KOUD, J.M. 1985 Pétrologie, minéralogie, métallogenie et géochimie des gîtes de cuivre du Niari au Congo. Strasbourg, Université Louis Pasteur. 181p. (Thèse pour le Doctorat).

MACKENZIE, R.M. 1971 The synthesis of birnessite, cryptomelane and some other oxides and hydroxides of manganese. Mineralogical Magazine, London, 38:294-502.
MATHIESON, A. McL. \& WADSLEY, A.D. 1950. The crystal structure of cryptomelane. American Mineralogist, Washington, D.C., 35(1/2):99-101.

PARISOT, J.C. 1989 L'altération lateritique de protores cuprifères au Brésil. France, Université Poitiers. 197p. (Thèse pour le Doctorat).

POTTER, R.M. \& ROSSMAN, G.R. 1979 The tetravalent manganese oxides: identification, hydratation and structural relationships by infrared spectroscopy. American Mineralogist, Washington, D.C., 64(11/12): 1199-1218.

RICHMOND, W.E. \& FLEISCHER, M. 1942 Cryptomelane a new name for the commonest of the "psilomelana" minerals. American Mineralogist, Washington, D.C., 27(5/6):607-610.

TOLEDO-GROKE, M.C. 1986 Intemperismo das rochas mineralizadas em cobre do Salobo $3 \alpha$, Serra dos Carajás: mecanismos de alteração dos minerais primários e localização do cobre nos produtos secundários. São Paulo, Instituto de Geociências/USP. 173p. (Tese de Doutoramento).

VALARELLI, J. V. 1967 O minério de manganês da Serra do Navio - Amapá. São Paulo, Fac. Fil. C. Letras, USP. (Tese de Doutoramento)

VEIGA, M.M. 1983 Propriedades geoquímicas da ligação cobre-óxidos hidratados de ferro: um estudo do minério alterado do Salobo $3 \alpha$ - Serra dos Carajás. Rio de Janeiro, Universidade Federal Fluminense. 182p. (Dissertação de Mestrado)

\section{Manuscrito recebido em novembro de 89}

- Maria Cristina Toledo-Groke - Universidade de São Paulo - Instituto de Geociências - Caixa Postal 20.899 - 01498 - São Paulo, SP - Brasil.

- Adolpho José Melfi - Universidade de São Paulo - Instituto Astronômico e Geofísico - Caixa Postal 30.627 - 01051

- São Paulo, SP - Brasil.

- Jean-Claude Parisot - ORSTOM e Laboratoire de Pétrologie de la Surface, Université Poitiers, 40, Av. du Recteur Pineau, Poitiers - França. 